\title{
Can laser treatment improve quality of life of hirsute women?
}

\author{
This article was published in the following Dove Press journal: \\ International Journal of Women's Health \\ 19 October 2017 \\ Number of times this article has been viewed
}

\author{
Narges Alizadeh' \\ Sharad Ayyoubi ${ }^{2}$ \\ Mohammadreza Naghipour ${ }^{3}$ \\ Rasool Hassanzadeh ${ }^{2}$ \\ Zahra Mohtasham-Amiri ${ }^{3}$ \\ Shirin Zaresharifi ${ }^{4}$ \\ Kaveh Gharaei Nejad' \\ 'Dermatology Department, School of \\ Medicine, Guilan University of Medical \\ Sciences, ${ }^{2}$ General Practice, School of \\ Medicine, Guilan University of Medical \\ Sciences, ${ }^{3}$ Community Medicine \\ Department, School of Medicine, \\ Guilan University of Medical Sciences, \\ Rasht, ${ }^{4}$ General Practitioner, School of \\ Medicine, Tehran University of Medical \\ Sciences, Tehran, Iran
}

Correspondence: Narges Alizadeh Dermatology Department, Razi Hospital, Sardarejangal AVN, Rasht, Iran Email narges.alizadeh7@gmail.com

\begin{abstract}
Background: Hirsutism can have negative impacts on psychosocial aspects of women's lives and reduce their quality of life (QOL). The aim of this study was to assess the QOL of these women during laser treatment.

Patients and methods: Eighty-eight women with unwanted facial hair underwent laser therapy. Each patient completed a questionnaire consisting of a modified Dermatology Life Quality Index (DLQI) and visual analog scale (VAS) before the first, third, and fifth sessions of laser therapy. Interval between the sessions was 4-6 weeks. Statistical analyses were done using SPSS software version 18.

Results: The DLQI scores before treatment, and at third and fifth sessions were $7.75 \pm 2.36$, $5.55 \pm 1.88$, and $4.14 \pm 0.64$, respectively $(P<0.0001)$. Also, VAS scores had a decreasing trend between the first and second treatment sessions as the mean patient VAS score fell from $10 \pm 0.04$ to $5.53 \pm 2.41(P<0.0001)$. The DLQI scores were significantly different according to areas of hair growth and number of involved areas. There were no significant differences with regard to response to treatment and mean of DLQI score according to the level of education, marital status, and employment status.
\end{abstract}

Conclusion: Hair removal with laser therapy can improve the QOL in hirsute women. Also, socioeconomic status does not affect the satisfaction rate of laser therapy for hair removal.

Keywords: hirsutism, laser, quality of life, satisfaction, psychosocial

\section{Introduction}

Hirsutism is defined as the growth of terminal hair in male androgen-dependent areas of women. ${ }^{1}$ The prevalence of hirsutism varies from $5 \%$ to $32 \%$ in different parts of the world and seems to be due to racial differences. ${ }^{2-7}$ The presence of hirsutism is a distressing symptom with a negative impact on psychosocial aspects and quality of life (QOL). ${ }^{8-11}$

Cosmetic procedures and drug therapy are used in the treatment of hirsutism. ${ }^{12}$ The basis of treatments in hirsutism is reduction of excess hair. The choice of a method depends on patient preference, adverse effects, degree of hirsutism, level of distress, previous treatments, and cost. ${ }^{13}$

The long-pulse alexandrite laser with wavelength of $755 \mathrm{~nm}$ is an effective laser for hair reduction. ${ }^{14-16}$ The aim of this study was to evaluate the effect of hair reduction in QOL of hirsute women during laser treatment.

\section{Patients and methods}

The study was approved by the local institutional review board of Guilan University of Medical Sciences. In this clinical study, 170 women who were referred to the laser treatment center in Guilan, 96 with facial hirsutism, were enrolled in this study. 
Eight patients discontinued the study and lost to follow-up, and 88 women completed the treatment.

The study was conducted in three phases: before laser therapy and before third and fifth sessions of treatment. The interval between sessions was 4-6 weeks. A written consent was obtained from each patient participating in this study. Pregnant patients, patients who used any medication to control hair growth, patients who used psychotherapeutic drugs during laser treatment, and patients younger than 18 years were excluded.

\section{Measuring tool}

All patients were asked to complete a modified Dermatology Life Quality Index (DLQI) and visual analog scale (VAS) before the first, third, and fifth sessions of laser therapy. The DLQI is calculated by summing the score of each question in the range between 0 and 30 . The higher the score the more the QOL is impaired. The VAS consisted of a $10 \mathrm{~cm}$ horizontal line with the terms "no hair" $(0)$ and "the hairiest ever" (10) at opposite ends; patients were asked to mark exactly where they thought they were on the line. The DLQI was analyzed as follows: $0-1=$ no effect at all on patient's life, $2-5=$ small effect on patient's life, $6-10=$ moderate effect on patient's life, $11-20=$ very large effect on patient's life, $21-30=$ extremely large effect on patient's life. ${ }^{17,18}$

\section{Treatment}

The patients then underwent a programmed laser therapy at 4-6-week intervals using the $755 \mathrm{~nm}$ long-pulsed alexandrite laser (Cynosure Apogee, Westford, MA, USA) with the Zimmer Cryo 5 cooling device. The settings used were determined by the Fitzpatrick skin type of each patient. A fluence of $20 \mathrm{~J} / \mathrm{cm}^{2}$ was used for types I and II, with $20 \mathrm{~ms}$ pulse duration and a $15 \mathrm{~mm}$ spot size; a fluence of $14 \mathrm{~J} / \mathrm{cm}^{2}$ was used for types III and IV, with $40 \mathrm{~ms}$ pulse duration. The fluence was changed in the range of $2-5 \mathrm{~J} / \mathrm{cm}^{2}$ in each session of treatment based on the patient's tolerance.

\section{Statistical analyses}

Statistical analyses were done using SPSS software version 18. All data were statistically analyzed by Student's $t$-test and repeated measure analysis of variance (ANOVA). Statistical significance was set at $P<0.05$.

\section{Results}

Among women with facial hirsutism referred for laser therapy, 88 women with a mean age of $29.2 \pm 0.6$ years were evaluated. More than half of them had academic education
Table I Demographic data and number of areas involved, of participants

\begin{tabular}{lll}
\hline Variable & Number & Percentage \\
\hline Age (years) & 48 & 54.5 \\
I8-27 & 31 & 35.2 \\
$28-37$ & 9 & 10.3 \\
$>37$ & & \\
Marital status & 41 & 46.6 \\
Married & 43 & 48.9 \\
Single & 4 & 4.5 \\
Other & & \\
Educational level & 41 & 46.6 \\
Diploma & 47 & 53.4 \\
Bachelor or higher & & \\
Employment & 22 & 25 \\
Housewife & 31 & 35.2 \\
Unemployed & 35 & 39.8 \\
Employee & & \\
Number of areas involved & 24 & 27.3 \\
I & 15 & 17 \\
2 & 18 & 20.5 \\
3 & 31 & 35.2 \\
4 & &
\end{tabular}

and $47.7 \%$ were married. Approximately $73 \%$ of the patients suffered from hirsutism in more than one area. Patients' demographics data are shown in Table 1.

In almost all patients, hirsutism had moderate to severe effect on patients' lives, and mean score of DLQI before the treatment was 7.75 \pm 2.36 . Repeated measure analysis showed that the DLQI and VAS scores were significantly different not only between the beginning and the end of treatment but also between the third and the fifth sessions of treatment ( $P=0.0001$; Table 2).

The mean DLQI scores according to the areas of hair growth, including cheek, parotid, mental, and submental regions, were reduced significantly during the three phases of study, but after comparison of the means between the areas, patients with mental and submental involvement had higher satisfaction rate to treatment in comparison with cheek and parotid areas $(P<0.01$; Table 3$)$.

Using one-way ANOVA, significant difference was determined between the mean DLQI scores based on the number of

Table 2 Mean Dermatology Life Quality Index (DLQI) and visual analog scale (VAS) during three phases of treatment

\begin{tabular}{|c|c|c|c|c|}
\hline Variable & $\begin{array}{l}\text { Before } \\
\text { treatment }\end{array}$ & $\begin{array}{l}\text { Before } \\
\text { third session }\end{array}$ & $\begin{array}{l}\text { Before } \\
\text { fifth session }\end{array}$ & $P$-value \\
\hline $\begin{array}{l}\mathrm{DLQI} \\
(\text { mean } \pm \mathrm{SD})\end{array}$ & $7.75 \pm 2.36 *$ & $5.55 \pm 1.88^{\#}$ & $4.14 \pm 0.64$ & $\begin{array}{l}0.000 I^{*} \\
0.00 I^{\#}\end{array}$ \\
\hline VAS $($ mean $\pm S D)$ & $10 \pm 0.04 *$ & $7.07 \pm 2.26^{\#}$ & $5.53 \pm 2.41$ & $0.000 I^{*, \#}$ \\
\hline
\end{tabular}

Notes: *Before treatment is significantly different from after treatment (before third

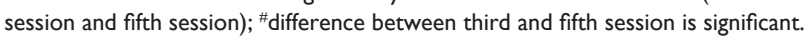


Table 3 Mean Dermatology Life Quality Index (DLQI) during three phases of treatment according to treated area

\begin{tabular}{lllll}
\hline $\begin{array}{l}\text { Treated area } \\
\text { (no) }\end{array}$ & $\begin{array}{l}\text { Before } \\
\text { treatment }\end{array}$ & $\begin{array}{l}\text { Before } \\
\text { third session }\end{array}$ & $\begin{array}{l}\text { Before } \\
\text { fifth session }\end{array}$ & P-value \\
\hline Cheek (35) & $9.57 \pm 8.5$ & $7.34 \pm 7.73$ & $5.28 \pm 6.22$ & $0.00 \mathrm{I}$ \\
Parotid (49) & $8.67 \pm 7.61$ & $7.08 \pm 6.8$ & $4.49 \pm 6.42$ & $0.000 \mathrm{I}$ \\
Mentum (80) & $7.87 \pm 6.52$ & $5.52 \pm 6.06^{*}$ & $4.08 \pm 4.8 I^{*}$ & $0.000 \mathrm{I}$ \\
Submental (66) & $8.09 \pm 6.68$ & $6.18 \pm 6.42^{\#}$ & $4.13 \pm 5.05^{\#}$ & $0.000 \mathrm{I}$ \\
\hline
\end{tabular}

Notes: *Before treatment is significantly different from after treatment (before third session and fifth session); ${ }^{\#}$ difference between third and fifth session is significant.

areas involved in the beginning of treatment, so the patients with more than three involved regions had significantly higher mean DLQI scores than other groups (Table 4).

There were no significant differences with regard to response to treatment and mean of DLQI scores according to the level of education, marital status, and employment status.

\section{Discussion}

Several studies have been conducted. However, some indicated improvements in QOL, while others showed no significant difference. ${ }^{18-20}$ In the study conducted by Loo and Lanigan, there had been a major improvement in DLQI score at 1-2 months but longer term benefit was not observed. ${ }^{20}$

It is important to recognize patients' perceptions of the severity of their hirsutism because their perception of facial hirsutism can differ greatly from doctors, nurses, and the wider population. ${ }^{19}$

The current study showed improvement in QOL as well as reduction of unwanted hair based on VAS after treatment by using alexandrite laser. The study did show that there was an average reduction in total DLQI of 3.6 points, indicating that laser hair removal therapy does have an impact on patients' QOL.

The higher satisfaction rate of laser therapy in patients with mental and submental involvement may be due to more effective treatments in these regions.

Table 4 Mean Dermatology Life Quality Index (DLQI) during treatment according to number of areas involved

\begin{tabular}{llll}
\hline $\begin{array}{l}\text { Number of } \\
\text { areas involved }\end{array}$ & $\begin{array}{l}\text { Before } \\
\text { treatment }\end{array}$ & $\begin{array}{l}\text { Before } \\
\text { third session }\end{array}$ & $\begin{array}{l}\text { Before } \\
\text { fifth session }\end{array}$ \\
\hline I & $6.2 \pm 5.1$ & $3.2 \pm 3.1$ & $3.2 \pm 3$ \\
2 & $7 \pm 2.8$ & $6 \pm 4.6$ & $3.9 \pm 3.6$ \\
3 & $7.1 \pm 3.1$ & $4.1 \pm 3.7$ & $2.8 \pm 2.4$ \\
4 & $9.6 \pm 3.9 *$ & $7.9 \pm 7.9^{*}$ & $5.6 \pm 4.6^{*}$ \\
\hline
\end{tabular}

Notes: Using repeated measure analysis of variance; *Four involved regions are significantly different from all other groups (before treatment, before third session and before fifth session) $P$-value $=0.016$.
Studies show that social fear in hirsute women can influence their participation in social activities. ${ }^{9} 10$ In our study, level of education and employment status were not feasible factors in improvement of DLQI in hirsute women.

\section{Conclusion}

It seems that laser therapy in hirsute women without any psychiatric disorders can result in improvement in QOL and increase of social and interpersonal activities. Also, socioeconomic status does not affect the response to treatment and mean of DLQI score in hirsute women.

\section{Acknowledgment}

We thank all the members at the Giluan Laser Center for their help in this research.

\section{Disclosure}

The authors report no conflicts of interest in this work.

\section{References}

1. Sachdeva S. Hirsutism: evaluation and treatment. Indian J Dermatol. 2010;55(1):3-7.

2. Nina O, Jerry S. Hair growth disorders. In: Goldsmith LA, Katz SI, Gilchrest BA, Paller AS, Leffel DJ, Wolff K, editors. Fitzpatrick's Dermatology in General Medicine. New York: McGraw Hill; 2012: 739-777.

3. Zargar AH, Wani AI, Masood SR, Laway BA, et al. Epidemiologic and etiologic aspect of hirsutism in Kashmiri women in the Indian subcontinent. Fertile Steril. 2002;77(4):674-678

4. Akhyani M, Daneshpazhooh M, Barzegari M, et al. Frequency of hirsutism in medical student in Tehran. Iran J Dermatol. 2006;9(37): 242-249.

5. Hashemipour M, Faghihimani S, Zolfaghary B, et al. Prevalence of polycystic ovary syndrome in girls aged 14-18 years in Isfahan, Iran. Horm Res. 2004;62:278-282.

6. Noorbala MT, Kefaie P. The prevalence of hirsutism in adolescent girls in Yazd, Central Iran. Iran Red Crescent Med. 2010;12(2):111-117.

7. Tehrani FR, Rashidi H, Azizi F. The prevalence of idiopathic hirsutism and polycystic ovary syndrome in the Tehran Lipid and Glucose Study. Reprod Biol Endocrinol. 2011;9:144.

8. Thomas SA, Fan AW, Pastore LM. A review of the impact of body image on quality of life in women with polycystic ovary syndrome. Int J Psychol Res. 2014;9(1):17-32.

9. Sonino N, Fava GA, Mani E, Belluardo P, Boscaro M. Quality of life of hirsute women. Postgrad Med J. 1993;69(809):186-189.

10. Lipton MG, Sherr L, Elford J, Rustin MH, Clayton WJ. Women living with facial hair: the psychological and behavioral burden. $J$ Psychosom Res. 2006;61(2):161-168.

11. Agnieska P, Violeta S, Ryszard P. Quality of life, mental health and selfesteem in hirsute adolescent females. J Psychosom Obstet Gynaecol. 2010;31(3):168-175.

12. Pasquali R, Gambineri A. Therapy of endocrine disease: treatment of hirsutism in the polycystic ovary syndrome. Eur J Endocrinol. 2014;170: R75-R90.

13. Goldberg DJ. Unwanted hair: evaluation and treatment with lasers and light source technology. Adv Dermatol. 1999;14:115-140.

14. Davoudi SM, Behnia F, Gorouhi F, et al. Comparison of long-pulsed alexandrite and Nd: YAG lasers, individually and in combination, for leg hair reduction. Arch Dermatol. 2008;144(10):1323-1327. 
15. Bouzari N, Tabatabai H, Abbasi Z, et al. Laser hair removal: comparison of long-pulsed Nd: YAG, long-pulsed alexandrite, and long-pulsed diode lasers. Dermatol Surg. 2004;30(4pt 1):498-502.

16. McGill DJ, Hutchison C, McKenzie E, McSherry E, Mackay IR. A randomised, split-face comparison of facial hair removal with the alexandrite laser and intense pulsed light system. Lasers Surg Med. 2007;39:767-772.

17. Finaly AY. Quality of life indices. Indian J Dermatol Venereal Leprol. 2004;70(3):143-148.
18. Conroy FJ, Venus M, Monk B. A qualitative study to assess the effectiveness of laser epilation using a quality-of-life scoring system. Clin Exp Dermatol. 2006;31(6):753-756.

19. Maziar A, Farsi N, Mandegarfard M, Babakoohi S, Gorouhi F, Dowlati Y. Unwanted facial hair removal with laser treatment improves quality of life of patients. J Cosmet Laser Ther. 2010;12(1):7-9.

20. Loo WJ, Lanigan SW. Laser treatment improves quality of life of hirsute female. Clin Exp Dermatol. 2002;27(6):439-441.

\section{Publish your work in this journal}

The International Journal of Women's Health is an international, peerreviewed open-access journal publishing original research, reports, editorials, reviews and commentaries on all aspects of women's healthcare including gynecology, obstetrics, and breast cancer. The manuscript management system is completely online and includes a very quick and fair peer-review system, which is all easy to use. Visit http://www.dovepress.com/testimonials.php to read real quotes from published authors.

Submit your manuscript here: http://www.dovepress.com/international-journal-of-womens-health-journal 